\title{
Statistical Optimization of Parameters Affecting Polyhydroxybutyrate (PHB) Recovery by Dispersion Method from Alcaligenes Cells and Its Characterization
}

\author{
Abhishek Dutt Tripathi ${ }^{1 *}$ and Suresh Kumar Srivastava ${ }^{2}$ \\ ${ }^{1}$ Centre of Food Science and Technology, Institute of Agricultural Sciences, Banaras Hindu University, Varanasi-221005, India \\ ${ }^{2}$ School of Biochemical Engineering, Indian Institute of Technology, Banaras Hindu University, Varanasi-221005, India
}

\begin{abstract}
In the present study, efforts have been made to optimize the three process variables i.e., incubation time, temperature of separation and hypochlorite concentration for enhanced polyhydroxybutyrate (PHB) recovery from Alcaligenes cells which may serve as precursor for bio-plastic production. Screening of bio-plastic (PHB) producing microorganism was done by TEM (Transmission electron microscopy). Initially, three recovery methods were applied to achieve efficient PHB recovery which included; Alkali treatment, ATPS (Aquas two phase separation (PEG 6000)/ $\left.\mathrm{KH}_{2} \mathrm{PO}_{4}\right)$ and chloroform-hypochlorite dispersion $(1: 1, \mathrm{v} / \mathrm{v})$. Maximum PHB recovery of $95 \pm 0.5 \%$ with $97.0 \pm 0.29 \%$ purity was obtained by dispersion method. In order to enhance the PHB recovery further, dispersion process was optimized using design expert (DX 8.0.6) software. PHB recovered under optimized physical condition comprising: incubation temperature $37^{\circ} \mathrm{C}$, incubation time $28 \mathrm{~h}$ and hypochlorite concentration of 30.0 , gave maximum PHB recovery of $98.2 \pm 0.05 \%$ against the predicted yield of $99.0 \pm 0.05 \%$ with $99.0 \%$ purity. Characterization of recovered polymer as PHB was done by FTIR (Fourier transform infrared microscopy) and NMR (Nuclear magnetic resonance spectroscopy).
\end{abstract}

Keywords: Alcaligenes cells; Process variables; Optimization; PHB recovery; $\mathrm{PHB}$ characterization

\section{Introduction}

Plastic finds tremendous applications in medical, food, pharmaceutical and agricultural commodities. According to Global Industry Analysts Inc. the global consumption of plastic materials will increase to 297.5 million tons by 2015 . Polyhydroxyalkanoates (PHAs) are thermoplastic polymers produced by diversified group of microorganisms [1,2], via the metabolic transformation of various carbon sources, under unbalanced growth conditions as intracellular reserve material $[3,4]$. PHAs can be categorized in three types i.e.; Short Chain Length (SCL), Medium Chain Length (MCL) and Long Chain Length (LCL) depending on the monomer size. SCL PHAs like Poly-3-Hydroxybutyrate (PHB) finds wider application in bio-plastic manufacturing due to their biodegradability and biocompatibility. Physical properties of $\mathrm{PHB}$ resemble to petrochemical-derived thermoplastic polypropylene; hence, $\mathrm{PHB}$ is considered as a potential replacement of certain traditional thermoplastics [5].

PHB can be synthesized chemically or by microorganisms and finds wider application in food packaging, biomedical and pharmaceutical industry. However, their use is currently limited owing to their high production cost. $\mathrm{PHB}$ production cost is dependent on several factors like substrate, chosen strain, cultivation strategy and downstream processing [6-9]. Inexpensive and scalable recovery schemes need to be devised to achieve low-cost production that is competitive with traditional thermoplastics [5]. Therefore, selection of the time-optimal process operating conditions to maximize the biomass production rate and PHA yield, is a problem of significant economic importance in a bioprocess [10]. There are many methods developed by researchers for the extraction, purification and recovery of PHA but the methods are still in consideration because of the high cost, complex process and non-environmental friendly aspects.

The efficient recovery process for PHA production depends on several factors. A high recovery and purity of recovered polymer with no reduction of molecular weight represents the efficiency of the recovery process.

In the present study, three recovery methods viz; alkali treatment, ATPS (aquas two phase separation) and chloroform-hypochlorite dispersion were applied to achieve efficient $\mathrm{PHB}$ recovery. In order to further enhance the PHB recovery, factors affecting the best recovery method were optimized and were characterized as PHB by FTIR and NMR.

\section{Materials and Methods}

\section{Bacterial strain and growth conditions}

Alcaligenes sp. NCIM 5025 was obtained from NCL (National Chemical Laboratory), Pune, India. Production media for PHB accumulation consisted of Mineral Salt Medium (MSM), comprising $40 \mathrm{~g} / \mathrm{l}$ cane molasses, $0.8 \mathrm{~g} / \mathrm{l}$ urea, $2.0 \mathrm{~g} / 1 \mathrm{KH}_{2} \mathrm{PO}_{4}, 0.6 \mathrm{~g} / \mathrm{l} \mathrm{Na} \mathrm{HPO}_{4}$, $1.0 \mathrm{~g} / \mathrm{l}, \mathrm{MgSO}_{4} .7 \mathrm{H}_{2} \mathrm{O}, 0.1 \mathrm{~g} / \mathrm{l}$ yeast extract and $1 \mathrm{ml} / \mathrm{l}$ of trace element $\left(1.3 \mathrm{~g} / \mathrm{l} \mathrm{ZnSO} \mathrm{Zn}_{4} .7 \mathrm{H}_{2} \mathrm{O}, 20.0 \mathrm{~g} / \mathrm{l} \mathrm{CaCl}_{2}, 0.2 \mathrm{~g} / \mathrm{FeSO}_{4} .7 \mathrm{H}_{2} \mathrm{O}, 0.6 \mathrm{~g} / \mathrm{l}\right.$ $\left(\mathrm{NH}_{4}\right)_{6} \mathrm{Mo}_{7} \mathrm{O}_{24} \cdot 4 \mathrm{H}_{2} \mathrm{O}$ and $0.6 \mathrm{~g} / \mathrm{l} \mathrm{H}_{3} \mathrm{BO}_{3}$ ). The carbon sources were sterilized separately at $121^{\circ} \mathrm{C}$ for $15 \mathrm{~min}$ and then aseptically added into the flask containing the other components at room temperature. The $\mathrm{pH}$ of the final culture medium was adjusted to $7 \pm 0.5$ using $0.1 \mathrm{~N} \mathrm{HCl} / 0.1 \mathrm{~N} \mathrm{NaOH}$ before bacterial inoculation. Production media

*Corresponding author: Abhishek Dutt Tripathi, Centre of Food Science and Technology, Institute of Agricultural Sciences, Banaras Hindu University, Varanasi-221005, India, Tel: +91-945-053-3651; E-mail: abhi_itbhu80@rediffmail.com

Received June 08, 2015; Accepted July 07, 2015; Published July 13, 2015

Citation: Tripathi AD, Srivastava SK (2015) Statistical Optimization of Parameters Affecting Polyhydroxybutyrate (PHB) Recovery by Dispersion Method from Alcaligenes Cells and Its Characterization. J Bioprocess Biotech 5: 238 doi:10.4172/2155-9821.1000238

Copyright: (c) 2015 Tripathi AD, et al. This is an open-access article distributed under the terms of the Creative Commons Attribution License, which permits unrestricted use, distribution, and reproduction in any medium, provided the original author and source are credited. 
was prepared in $250 \mathrm{ml}$ conical flask containing $100 \mathrm{ml}$ mineral salt medium. $5 \mathrm{ml}$ of the seed of each bacterial strain inoculums were added into different conical flasks containing $100 \mathrm{ml}$ of production medium and incubated at $150 \mathrm{rpm}, 37^{\circ} \mathrm{C}$ for $48 \mathrm{~h}$. Samples were extracted for analysis at different time interval viz; 24,48 and $72 \mathrm{~h}$ respectively.

\section{Analytical study}

Dry cell mass, $\mathrm{PHB}$ estimation: $20 \mathrm{ml}$ culture broth was centrifuged at $10,000 \mathrm{rpm}$ for $10 \mathrm{~min}$ at $4^{\circ} \mathrm{C}$ and cell pellet was obtained. The cell pellet was washed with saline water $(\mathrm{NaCl}, 0.8 \%(\mathrm{wt} / \mathrm{vol}))$ and then dried in aluminium weighing dish at $90^{\circ} \mathrm{C}$ for $24 \mathrm{hr}$. PHB estimation was done by gas chromatography (Neukon 5700, Detector-FID, Column-2 $\mathrm{m}$ in length, External diameter-30 mm, internal diameter-2 $\mathrm{mm}$, Porapack OV-101) as reported in our previous research paper [11].

PHB extraction: PHB was extracted by using alkali treatment, ATPS and chloroform-hypochlorite extraction method. Pure PHB was obtained by non solvent precipitation and filtration. The non solvent used was a mixture of methanol and water (7:3, vol/vol). Filtration was done using membrane filters (mesh size, $2 \mu \mathrm{m}$, millipore).

PHB recovery by alkali treatment: Dry cell mass obtained after different time interval of cultivation was subjected to alkali treatment. $0.1 \mathrm{~N}$ sodium hydroxide solution was taken to estimate the recovery and purity of samples at $25^{\circ} \mathrm{C}$.

PHB recovery by ATPS (Aquas two Phase separation system): Two Phase system was developed by using $26 \% \mathrm{w} / \mathrm{v}$ polyethylene glycol (PEG 6000) and 20\% (w/v) $\mathrm{KH}_{2} \mathrm{PO}_{4}$. The standard PHB of concentrations $3.0 \mathrm{~g} / \mathrm{l}$ was used for partitioning in ATPS made by PEG 6000 and $\mathrm{KH}_{2} \mathrm{PO}_{4}$ ATPS $(10 \mathrm{ml})$ were prepared by taking point at the center of the tie line of bimodal curve. The PEG phase was separated by disposable syringe and transferred to another flask $(100 \mathrm{ml})$ and the flask was kept in rotation at $200 \mathrm{rpm}$ for 10 minutes again. The PHB on the top was separated and analyzed. The salt phase was also separated and analyzed for PHB concentration and partition coefficient $\mathrm{K}_{\mathrm{d}}$ was calculated using formulae.

$$
K d=\frac{P H B \text { in } P E G \text { phase }(\mathrm{g} / \mathrm{l})}{P H B \text { in aquas phase }(\mathrm{g} / \mathrm{l})}
$$

PHB recovery by using dispersions of sodium hypochlorite and chloroform: $10 \mathrm{ml}$ of culture medium was placed in a $15 \mathrm{ml}$ centrifugal tube and cells were harvested by centrifugation at $4500 \mathrm{rpm}$ for $10 \mathrm{~min}$. The harvested cells ( $1.0 \mathrm{~g}$ dry cell weight) were treated with dispersion of $50 \mathrm{ml}$ of chloroform and $50 \mathrm{ml}$ of sodium hypochlorite solution. The concentrations of sodium hypochlorite solution used were $30 \%$ $(\mathrm{v} / \mathrm{v})$. After that the mixture was agitated at $30^{\circ} \mathrm{C}$ for $90 \mathrm{~min}$. It was centrifuged at $8,000 \mathrm{rpm}$ for $10 \mathrm{~min}$. The resulting PHB Containing bottom Phase (chloroform Phase) was withdrawn and added into a non-solvent solution (70\% methanol in water). The PHB filtered was recovered by filtration (Whatman no. 1 filter paper) and then dried at $70^{\circ} \mathrm{C}$ for $5 \mathrm{~h}$

Determination of purity and recovery yield: Recovery yield and purity in different extraction techniques were determined by following formulae

$$
\begin{aligned}
& \% \text { purity }=\frac{\text { Amount of } P H B \text { after re covery }}{\text { Amount of total dry matter after re covery }} \times 100 \\
& \% \text { Re covery }=\frac{\text { Amount of } P H B \text { re covered }}{\text { Total amount of } P H B \text { in } \text { the cell }} \times 100
\end{aligned}
$$

Preparation of samples for TEM analysis: Samples were collected after $48 \mathrm{~h}$ of fermentation and were fixed with $2.0 \%$ glutaraldehyde solution to observe the intracellular granule under electron microscope. Sample preparation, cell fixation, sectioning and visualization were done by method as reported in our previous study [12].

Sample preparation for FTIR analysis: Extracted PHB granules were dissolved in isotonic saline solution $\left(30 \mathrm{~kg} \mathrm{~m}^{-3}\right)$ and then $20 \mu \mathrm{L}$ of the solution was deposited on $\mathrm{KBr}$ disc. The depositors were then dried and IR spectra was recorded with a Bruker model IFS-55 FTIR spectrometer coupled to a Bruker IR microscope fitted with an IBM compatible PC running OPUS, Version 2.2 software.

H $^{1}$ NMR study of the molecular structure of PHB: The $500 \mathrm{MHz}$ ${ }^{1} \mathrm{H}$ NMR spectrum of PHB was obtained by using a Bruker model AMXFT NMR spectroscope. A PHB solution was prepared by using $\mathrm{CDCl}$ at a concentration of $2 \%(\mathrm{wt} / \mathrm{vol})$. The spectra were recorded at $25^{\circ} \mathrm{C}$ with a pulse repetition time of $3 \mathrm{~s}$. All ${ }^{1} \mathrm{H}$ NMR spectra were recorded at $30^{\circ} \mathrm{C}$ on a Bruker AM300-WB spectrometer (Wissembourg, France) equipped with an Aspect 3,000 computer using a $5 \mathrm{~mm}{ }^{1} \mathrm{H} /{ }^{13} \mathrm{C}$ dual probe. Proton spectra were recorded at $300.13 \mathrm{MHz}$ with a spectral width of $2,840 \mathrm{~Hz}$ over $16 \mathrm{~K}$ data points. A $66^{\circ}$ pulse angle was used. No apodization was used for ${ }^{1} \mathrm{H}$ interferograms. The measurements of spin-lattice relaxation time $\left(\mathrm{T}_{1}\right)$ were carried out by means of the inversion recovery method $\left(180^{\circ}-\mathrm{t}\right.$ (variable) $-90^{\circ}$-free induction decay). Data were averaged over 32 acquisitions with PHBse cycling and a recycle delay dependent on the internal standard at a concentration of $1.0 \% \mathrm{v} / \mathrm{v}$ in $\mathrm{CDCl}_{3}$, to avoid saturation. $\mathrm{T}$, values were calculated after examination of peak intensities using the TlCAL Bruker program. Chemical shifts were referenced to the internal reference TMS.

\section{Result and Discussion}

\section{Screening of PHB producing microbe}

Intracellular granule biosynthesis in Alcaligenes sp. was done by TEM. Figure 1 represents TEM images (magnification $100 \mathrm{~nm}$ ) at different time interval which showed Alcaligenes cell filled with large sized PHB granules attached to membrane vesicle and in the cytoplasm obtained after $48 \mathrm{~h}$ of cultivation.

\section{PHB recovery by three extraction methods}

PHB granules obtained were by three extraction methods viz; alkali treatment, ATPS method and chloroform-hypochlorite dispersion. Chlorinated solvent extraction (hypochlorite-chloroform dispersion) gave maximum $\mathrm{PHB}$ recovery and purity of $95.0 \pm 0.5$ and $97.0 \pm 0.29 \%$, respectively in comparison to alkali treatment and ATPS extraction (Table 1).

\section{Statistical optimization of parameters affecting PHB recovery by chloroform-hypochlorite dispersion}

PHB recovery from chloroform and hypochlorite dispersion is dependent on three parameters viz., incubation time, temperature of separation and hypochlorite concentration. In order to enhance PHB recovery, optimization of these parameters viz., incubation time, temperature of separation and hypochlorite concentration was performed by CCRD.

\section{Experimental design}

A five-level-three factor Central Composite Rotary Design (CCRD) was obtained by using the software (Minitab 16) to find out the interactive effect of three process variables viz; temperature, incubation 
time and hypochlorite concentration on PHB recovery (Table 2). Twenty set of experiment were designed by Minitab 16 software at different levels of three parameters (Table 3)

\section{Recovery Model}

Table 3 represents the design matrix in actual terms and experimental results of cell mass and PHB content in the Alcaligenes sp. by the CCRD with 8 factorial points, 6 axial points and 6 central points. Maximum PHB recovery of $96.0 \pm 0.35 \%$ was obtained in the trial no 3 , comprising temperature $\left(35^{\circ} \mathrm{C}\right)$, hypochlorite concentration $(30.0 \%$ $\mathrm{v} / \mathrm{v})$ and incubation period $(26 \mathrm{~h})$ (Table 3$)$. The regression analysis of experimental design demonstrated that the linear model terms (A temperature and incubation time $\mathrm{B})$, quadratic model terms $\left(\mathrm{A}^{2,} \mathrm{~B}^{2}\right.$ and $\left.\mathrm{C}^{2}\right)$ and interactive model term $(\mathrm{BC})$ were significant $(\mathrm{p}<0.05)($ Table 4). However, the linear model term $\mathrm{C}$ and interactive model terms $(\mathrm{AB}$ and $\mathrm{AC}$ ) were found to be insignificant $(\mathrm{P}>0.05)$ (Table 4).

The experimental data obtained from the design were analyzed by the response surface regression procedure using the following secondorder polynomial equation:

$$
Y_{i}=\beta_{0}+\sum \beta_{i} x_{i}+\sum \beta_{i i} x_{i}^{2}+\sum \beta_{i j} x_{i} j_{i}
$$

Where $Y_{i}$ was the predicted response, $x_{i} x_{i}$ were independent variables, $\beta_{0}$ was the offset term, $\beta_{i}$ was the linear coefficient, $\beta_{i i}$ was the quadratic coefficient and $\beta_{i j}$ was the interaction coefficient. Applying multiple regression analysis, the results were fitted to second order polynomial equation. The mathematical regression model for PHB recovery from Alcaligenes $s p$. fitted in the terms of coded variables was obtained as follows:

$\mathrm{Y}(\mathrm{PHB}$ recovery $)=+45.9942+1.59584 \quad \mathrm{~A}+0.846288 \mathrm{C}+0.638159$ B- $0.0188385 \quad \mathrm{~A}^{2}-0.0148743 \quad \mathrm{~B}^{2}-0.0108318 \quad \mathrm{C}^{2}-0.00187500 \quad$ AB$0.00397727 \mathrm{AC}+0.00426136 \mathrm{BC}$

Where, $\mathrm{Y}$ is the response in terms of PHB content. Coded terms $\mathrm{A}, \mathrm{B}$ and $\mathrm{C}$ represents temperature, incubation time and hypochlorite concentration, respectively.

\section{ANOVA}

Table 5 represents ANOVA of results of quadratic models. Analysis of variance (ANOVA) was used to estimate the statistical parameters. The second order polynomial equation was used to fit the experimental data. The significance of the model equation and model terms were evaluated by F-test. The quality of the fit of the polynomial equation was expressed by the coefficient of determination $\left(\mathrm{R}^{2}\right)$, adjusted and "adequate precision". The model F-value of 21.30 depicts that model was significant. Lack of fit value of 34.88 implies that the lack of fit is not significant relative to pure error. The fit of model was also expressed by the coefficient of determination $\mathrm{R}^{2}$, which was found to be 0.9505 , indicating that the $95.05 \%$ of the variability in the response can be explained by the model. The "pred R-squared of 0.8916 is in reasonable agreement with the "Adj R-Squared" of 0.9008. "Adeq Precision" measures signal to noise $(\mathrm{S} / \mathrm{N})$ ratio and its value obtained in the present model was found to be 17.25 , which indicates an adequate signal ( $\mathrm{S} / \mathrm{N}$ ratio $>4$ is desirable). The obtained results clearly suggest that quadratic model could be used to navigate the design space.

\section{Interactive effect of process variables on $\mathrm{PHB}$ recovery}

The fitted polynomial equation was expressed as three dimensional surface plots to visualize the relationship between the responses and the experimental levels of each factor used in the design. Interactive effect of different process variables were studied for $\mathrm{PHB}$ recovery by using $2 \mathrm{D}$ contour plots and $3 \mathrm{D}$ response surface. Figure $2 \mathrm{~A}$ represents the interactive effect of temperature and incubation time on $\mathrm{PHB}$ recovery. It can be clearly deduced from $3 \mathrm{D}$ surface and contour plot (Figure $2 \mathrm{~A}$ and $2 \mathrm{~B}$ ) that increase in temperature and incubation time, enhanced $\mathrm{PHB}$ recovery up to $40^{\circ} \mathrm{C}$ and $30 \mathrm{~h}$, respectively. However, further increase in these two process variables decreased $\mathrm{PHB}$ recovery which is in agreement with previous report, where increased temperature $\left(>41^{\circ} \mathrm{C}\right)$ decreased the $\mathrm{PHB}$ content probably due to polymer degradation and excessive cell lysis at elevated temperature [13]. Figure $3 \mathrm{~A}$ represents the interactive effect of temperature and hypochlorite concentration on $\mathrm{PHB}$ recovery, which showed enhanced PHB recovery at suboptimal level of two process variables (temperature $37^{\circ} \mathrm{C}$ and hypochlorite concentration 30\%). Further increase in temperature and hypochlorite concentration showed decreased $\mathrm{PHB}$ recovery which is represented by convergence of curve towards boundary of 3D plot (Figure 3A). Contour plot representing interactive effect of temperature and hypochlorite concentration confirmed the above finding that $\mathrm{PHB}$ recovery was maximum at $30 \%$ hypochlorite concentration while keeping incubation time at zero level of $26 \mathrm{~h}$ (Figure 3B). PHB recovery increased rapidly up to $30 \%$ hypochlorite concentration and $37^{\circ} \mathrm{C}$ temperature and then showed decreasing trend. Previously $91 \%$ PHB recovery was obtained from Alcaligenes eutrophus using 30\% hypochlorite solution under similar condition [14].

Incubation time and hypochlorite concentration showed significant influence on PHB recovery in Alcaligenes sp., when considered as individual process variable $(\mathrm{p}<0.05)$, However, interactive effect of incubation period and hypochlorite concentration was insignificant ( $\mathrm{p}>0.05$ ). Figure $4 \mathrm{~A}$ and $4 \mathrm{~B}$ represented interactive effect of two parameters (incubation time and hypochlorite concentration) on PHB recovery which showed that PHB recovery enhanced till $30 \%$ hypochlorite concentration. This suggests that chloroform can

\begin{tabular}{|l|l|l|l|}
\hline S.No & Recovery process & PHB Recovery (\%) & PHB purity (\%) \\
\hline 1. & Alkali treatment & $80.0 \pm 1.04$ & $91.0 \pm 0.58$ \\
\hline 2. & $\begin{array}{l}\text { Chlorinated solvent extraction } \\
\text { (chloroform-hypochlorite } \\
\text { dispersion) }\end{array}$ & $95.0 \pm 0.5$ & $97.0 \pm 0.29$ \\
\hline 3. & $\begin{array}{l}\text { Aquas two phase separation } \\
\text { (ATPS) }\end{array}$ & $90.0 \pm 1.0$ & $95.0 \pm 0.76$ \\
\hline
\end{tabular}

Table 1: Comparison of three recovery process based on percentage recovery and purity.

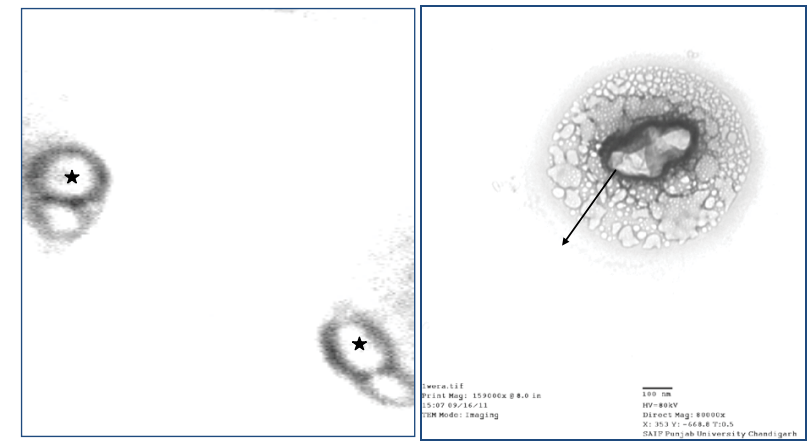

Figure 1: TEM analysis of Alcaligenes sp. membrane vesicle after negative staining. TEM analysis of Alcaligenes $s p$. after $48 \mathrm{~h}$ of inoculation. Asterisk represents large PHB granules. Alcaligenes cell filled with granules. Arrows point to intracellular granules present inside membrane vesicle. Arrow represented the large PHB granule inside the vesicle (magnification $100 \mathrm{~nm}$ ). 
Citation: Tripathi AD, Srivastava SK (2015) Statistical Optimization of Parameters Affecting Polyhydroxybutyrate (PHB) Recovery by Dispersion Method from Alcaligenes Cells and Its Characterization. J Bioprocess Biotech 5: 238 doi:10.4172/2155-9821.1000238

Page 4 of 7

\begin{tabular}{|c|c|c|c|c|c|c|c|}
\hline \multirow[t]{2}{*}{ S.No } & \multirow[t]{2}{*}{ Variable } & \multirow[t]{2}{*}{ Code } & \multicolumn{5}{|c|}{ Levels } \\
\hline & & & $-2(-\alpha)$ & -1 & 0 & 1 & $2(+\alpha)$ \\
\hline 1. & Temperature $\left({ }^{\circ} \mathrm{C}\right)$ & A & 18.18 & 25.00 & 35.00 & 45.00 & 51.82 \\
\hline 2. & Incubation time (h) & $B$ & -10.99 & 4.00 & 26.00 & 48.00 & 62.99 \\
\hline 3. & Hypochlorite concentration (\%) & $\mathrm{C}$ & -3.64 & 10.00 & 30.00 & 50.00 & 63.64 \\
\hline
\end{tabular}

Table 2: Levels of physical factors used for optimization of three factors affecting PHB recovery

\begin{tabular}{|c|c|c|c|c|c|c|c|}
\hline Run Order & Run & Levels & Levels & Temperature $\left({ }^{\circ} \mathrm{C}\right)$ & $\begin{array}{c}\text { Hypochlorite } \\
\text { Concentration }(\% \mathrm{v} / \mathrm{v})\end{array}$ & $\begin{array}{l}\text { Incubation period } \\
\text { (h) }\end{array}$ & PHB recovery (\%) \\
\hline 17 & 1 & 0 & 1 & 35.0000 & 30.0000 & 26.0000 & $94.0 \pm 0.25$ \\
\hline 19 & 2 & 0 & 1 & 35.0000 & 30.0000 & 26.0000 & $95.0 \pm 0.21$ \\
\hline 20 & 3 & 0 & 1 & 35.0000 & 30.0000 & 26.0000 & $96.0 \pm 0.35$ \\
\hline 5 & 4 & 1 & 1 & 25.0000 & 10.0000 & 48.0000 & $83.0 \pm 0.4$ \\
\hline 6 & 5 & 1 & 1 & 45.0000 & 10.0000 & 48.0000 & $88.0 \pm 0.15$ \\
\hline 10 & 6 & -1 & 1 & 51.8179 & 30.0000 & 26.0000 & $93.0 \pm 0.38$ \\
\hline 3 & 7 & 1 & 1 & 25.0000 & 50.0000 & 4.0000 & $78.0 \pm 0.2$ \\
\hline 8 & 8 & 1 & 1 & 45.0000 & 50.0000 & 48.0000 & $86.0 \pm 0.35$ \\
\hline 7 & 9 & 1 & 1 & 25.0000 & 50.0000 & 48.0000 & $89.0 \pm 0.26$ \\
\hline 9 & 10 & -1 & 1 & 18.1821 & 30.0000 & 26.0000 & $90.0 \pm 0.25$ \\
\hline 11 & 11 & -1 & 1 & 35.0000 & -3.6359 & 26.0000 & $78.0 \pm 0.50$ \\
\hline 4 & 12 & 1 & 1 & 45.0000 & 50.0000 & 4.0000 & $85.0 \pm 0.42$ \\
\hline 15 & 13 & 0 & 1 & 35.0000 & 30.0000 & 26.0000 & $95.0 \pm 0.38$ \\
\hline 12 & 14 & -1 & 1 & 35.0000 & 63.6359 & 26.0000 & $82.0 \pm 0.53$ \\
\hline 14 & 15 & -1 & 1 & 35.0000 & 30.0000 & 62.9994 & $85.0 \pm 0.53$ \\
\hline 13 & 16 & -1 & 1 & 35.0000 & 30.0000 & -10.9994 & $79.0 \pm 0.3$ \\
\hline 16 & 17 & 0 & 1 & 35.0000 & 30.0000 & 26.0000 & $95.5 \pm 0.21$ \\
\hline 2 & 18 & 1 & 1 & 45.0000 & 10.0000 & 4.0000 & $88.0 \pm 0.25$ \\
\hline 18 & 19 & 0 & 1 & 35.0000 & 30.0000 & 26.0000 & $94.0 \pm 0.25$ \\
\hline 1 & 20 & 1 & 1 & 25.0000 & 10.0000 & 4.0000 & $86.0 \pm 0.40$ \\
\hline 17 & 1 & 0 & 1 & 35.0000 & 30.0000 & 26.0000 & $95.0 \pm 0.32$ \\
\hline
\end{tabular}

Table 3: Central composite design of independent variables for the optimization of parameters affecting PHB recovery from Alcaligenes $s p$.

\begin{tabular}{|c|c|c|c|}
\hline Term & Coef & SE Coef & T \\
\hline Constant & 97.7790 & 0.8921 & 109.605 \\
\hline Temperature & 1.1749 & 0.5929 & 1.985 \\
\hline Hypochlorite concentration & -0.0200 & 0.5919 & -0.034 \\
\hline Incubation time & 1.3979 & 0.5919 & -000 \\
\hline Temperature*Temperature & -1.8838 & 0.5762 & -3.270 \\
\hline Hypochlorite concentration* Hypochlorite \\
concentration
\end{tabular}

Table 4: Estimated regression coefficient for recovery (\%).

\begin{tabular}{|c|c|c|c|c|}
\hline \multirow{2}{*}{ Variables } & Before & After & \multicolumn{2}{|c|}{ PHB recovery (\% DCW) } \\
\cline { 2 - 4 } & & & Before & Prter \\
\hline Temperature $\left({ }^{\circ} \mathrm{C}\right)$ & & & 96.00 & $99.0 \pm 0.10$ \\
\hline Incubation time (h) & 37.00 & 36.00 & \\
\hline Hypochlorite concentration (\%) & 30.00 & 28.00 & & \\
\hline
\end{tabular}

Table 5: Analysis of variance for recovery (\%).

protect the $\mathrm{PHB}$ molecules from being digested by hypochlorite if a moderate hypochlorite concentration is used. Maximum PHB recovery was obtained below $30 \mathrm{~h}$ of incubation, which indicates that $\mathrm{PHB}$ degradation is more prominent than $\mathrm{PHB}$ release from cell biomass after $30 \mathrm{~h}$ of treatment. PHB purity was found to be $99 \%$ at
$30 \%$ hypochlorite concentration which is higher in comparison to previous report [14]. Hann et al. [15] reported $88 \%$ and $93 \%$ purity in PHB obtained from Alcaligenes eutrophus and recombinant E.coli using $20 \%$ sodium hypochlorite and chloroform dispersion [15]. PHB recovery of $80 \%$ with $98.3 \%$ purity was achieved after $72 \mathrm{~h}$ of extraction 
Citation: Tripathi AD, Srivastava SK (2015) Statistical Optimization of Parameters Affecting Polyhydroxybutyrate (PHB) Recovery by Dispersion Method from Alcaligenes Cells and Its Characterization. J Bioprocess Biotech 5: 238 doi:10.4172/2155-9821.1000238

Page 5 of 7

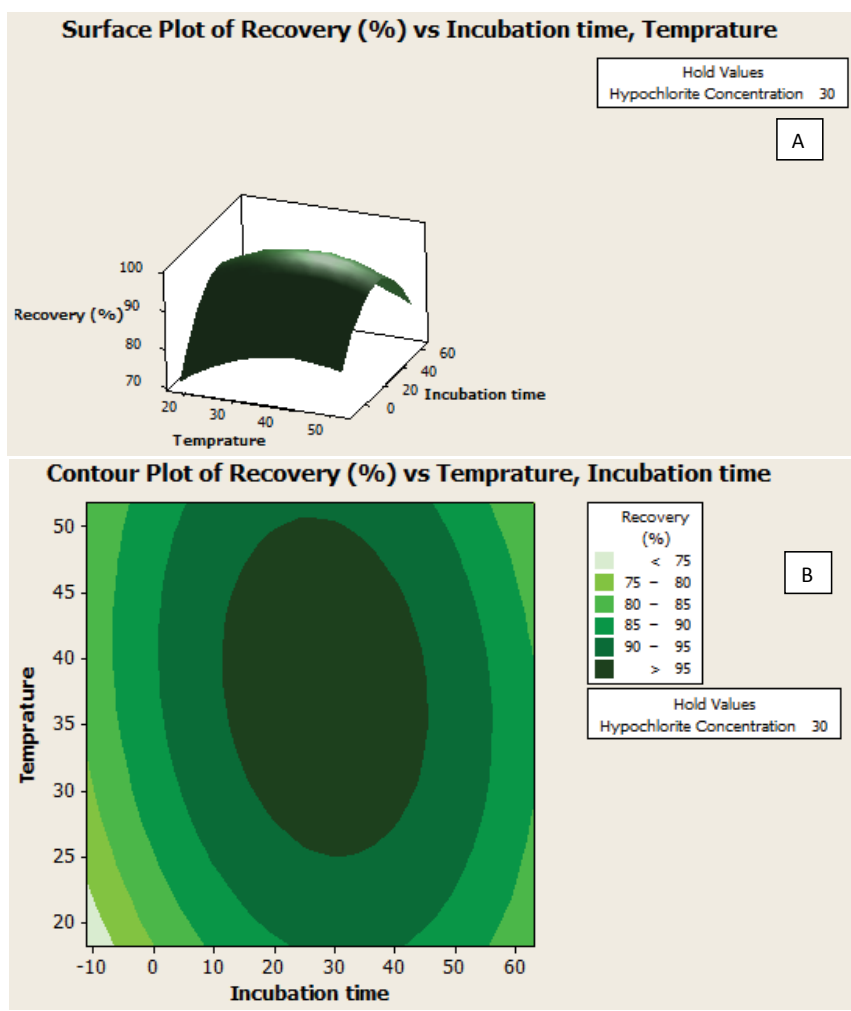

Figure 2: A) Surface plot of recovery between temperature and incubation time. B) Contour plot of recovery between temperature and incubation time.

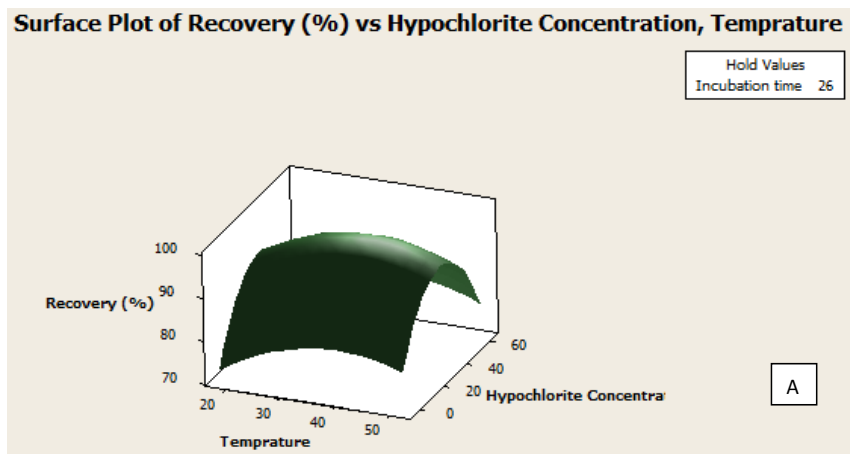

Contour Plot of Recovery (\%) vs Hypochlorite Concentration, Temprature

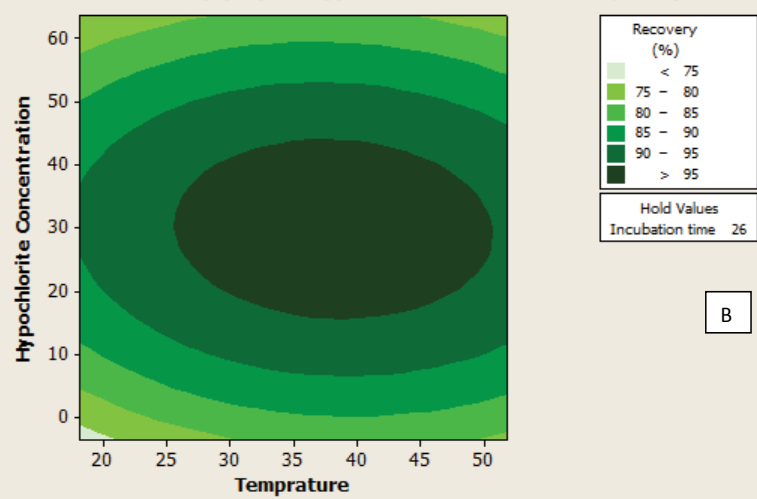

Figure 3: A) Surface plot of recovery between hypochlorite concentration and temperature B) Contour plot of recovery between hypochlorite concentration and temperature.

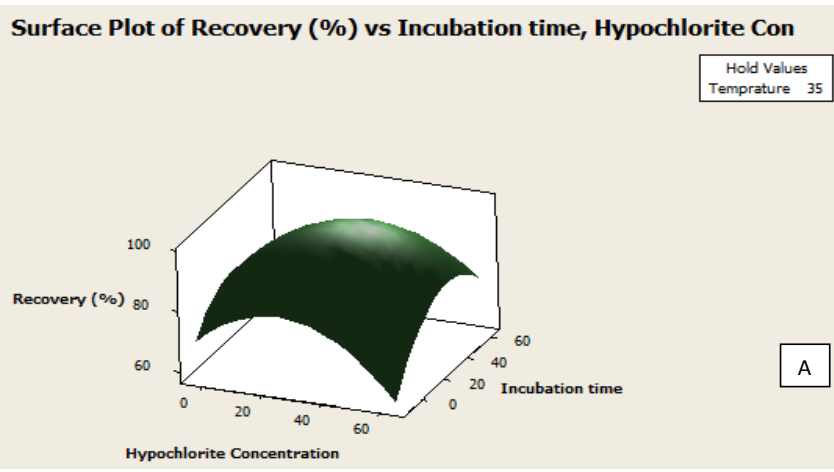

Contour Plot of Recovery (\%) vs Hypochlorite Con, Incubation time

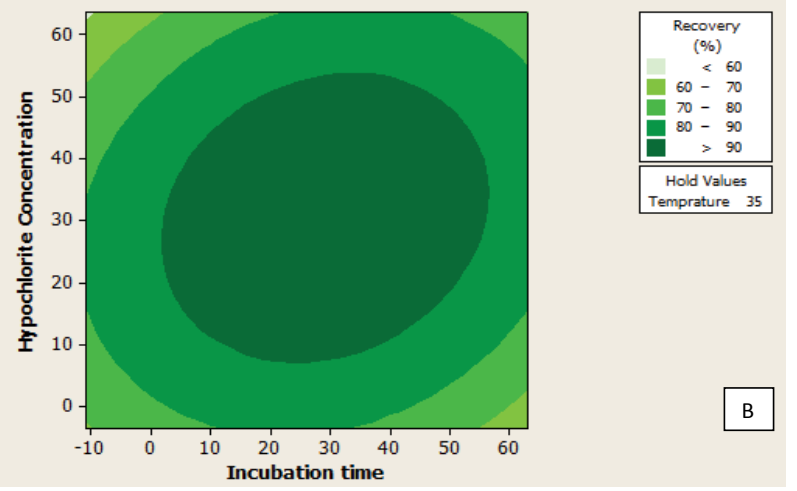

Figure 4: A) Surface plot of recovery between hypochlorite concentration and incubation time. B) Contour plot of recovery between hypochlorite concentration and incubation time.

with chloroform at $30^{\circ} \mathrm{C}$ [13]. PHB yield of $70 \%$ with $90 \%$ purity was obtained in solvent extraction with 1,2 dichloroethane with acetone pretreatment for $24 \mathrm{~h}$ at $83^{\circ} \mathrm{C}[16]$.

\section{Model verification}

CCRD used for the optimization of the three parameters for enhanced PHB recovery revealed the maximum PHB recovery of $98.20 \pm 0.05 \%$ recorded against the predicted yield of $99.0 \pm 0.10 \%$ at optimum condition comprising: incubation temperature $37^{\circ} \mathrm{C}$, incubation time $28 \mathrm{~h}$ and hypochlorite concentration of $30 \%$. It can be visualized from Table 5 that the predicted and experimental PHB content after optimization were well in agreement. The desirability was found to be 0.95 which showed $95 \%$ validation between observed and experimental value.

\section{Characterization of $\mathrm{PHB}$}

Characterization of recovered polymer was done by FTIR and $\mathrm{H}^{1} \mathrm{NMR}$. FTIR spectra predicted the presence of functional groups of $\mathrm{PHB}$ i.e. aliphatic $\mathrm{C}-\mathrm{H},=\mathrm{O}$ stretching, $=\mathrm{C}-\mathrm{H}$ deformation, $=\mathrm{C}-\mathrm{H},=\mathrm{CH}$, $=\mathrm{C}-\mathrm{O}$ etc. In pure $\mathrm{PHB}$ samples the band appeared at $1460 \mathrm{~cm}^{-1}$ which correspond to the asymmetrical deformation of $\mathrm{C}-\mathrm{H}$ bond in $\mathrm{CH}_{2}$ groups including $\mathrm{CH}_{3}$ groups at $1379 \mathrm{~cm}^{-1}$ [17]. The band at 1726 and $1280 \mathrm{~cm}^{-1}$ corresponded to the stretching of the $\mathrm{C}=\mathrm{O}$ bond, whereas a series of intense bands located at $1000-1300 \mathrm{~cm}^{-1}$ reads the stretching of the C-O bond of the ester group. PHB extracted from Alcaligenes $s p$. by ATPS method and chloroform-hypochlorite dispersion (Figure $5 \mathrm{~A}$ and $5 \mathrm{~B}$ ) resembled commercial PHB because there was a strong adsorption band at $1244 \mathrm{~cm}^{-1}$ which is characteristic for ester bonding. Other adsorption bands at 1392, 1486, 2922, 1726 and $3760 \mathrm{~cm}^{-1}$ for 


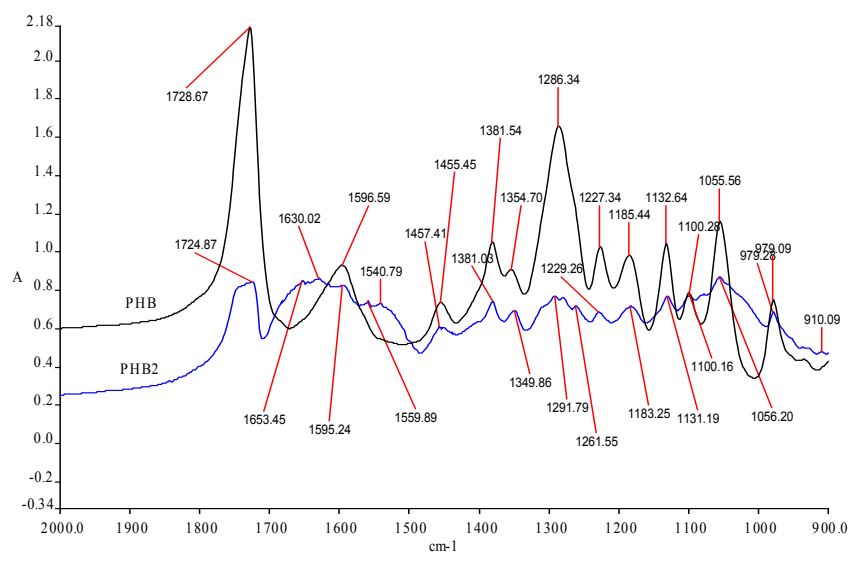

Figure 5a: A. FTIR (Fourier Transform Infrared Spectroscopy) showing PHB produced by Alcaligenes sp. NCIM 5085 after $24 \mathrm{~h}$ of production phase recovered by ATPS method.

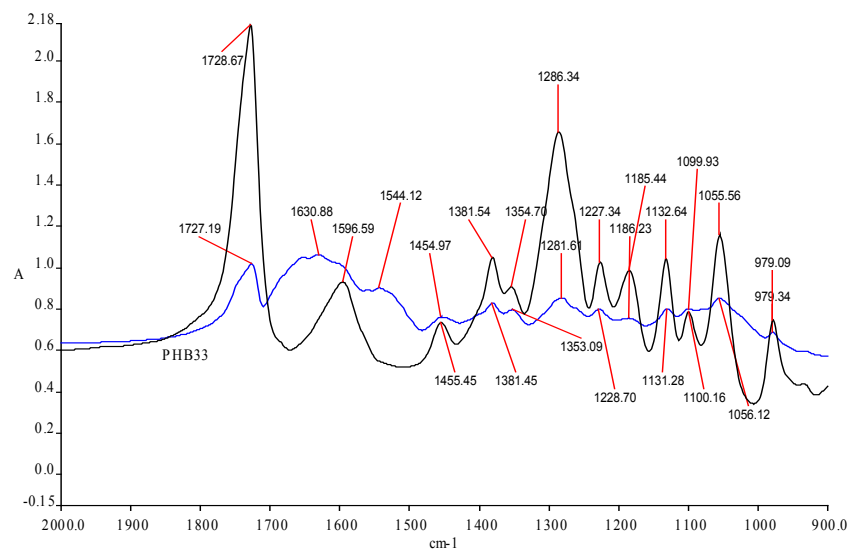

Figure 5a: FTIR (Fourier Transform Infrared Spectroscopy) of PHB produced by Alcaligenes sp. NCIM 5085 by hypochlorite-chloroform dispersion method.

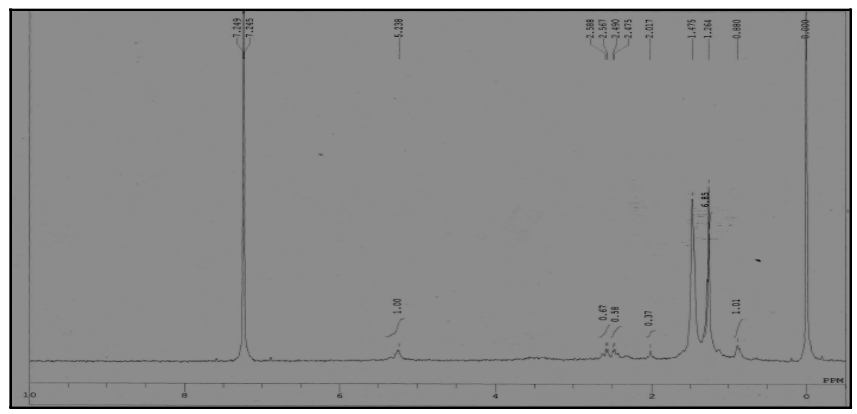

$\delta 5.26(1 \mathrm{H}, \mathrm{m}, \mathrm{CH}), \delta 2.52\left(2 \mathrm{H}, \mathrm{d}, \mathrm{CH}_{2}\right), \delta 1.274\left(3 \mathrm{H}, \mathrm{s}, \mathrm{CH}_{3}\right)$

Figure 6: ${ }^{1} \mathrm{H}-\mathrm{NMR}\left(\mathrm{D}_{2} \mathrm{O}\right)$ of polyhydroxyalkanoate extracted from Alcaligenes sp. in optimized medium.

$\mathrm{CH}_{3},-\mathrm{CH}_{2},-\mathrm{CH}, \mathrm{C}=\mathrm{O}$, and $\mathrm{O}-\mathrm{H}$ groups respectively were similar to the absorption band of commercial PHB. Extracted polymer was characterized as PHB by NMR analysis. $\mathrm{H}^{1}$ NMR analysis of extracted polymer showed a doublet at $1.53 \mathrm{ppm}$ representing the methyl group $\left(\mathrm{CH}_{3}\right)$ coupled to one proton while a doublet of quadruplet at 2.75 ppm resulted from methylene group $\left(\mathrm{CH}_{2}\right)$ adjacent to an asymmetric carbon atom bearing a single proton. The third signal was multiplet at $5.52 \mathrm{ppm}$, which is attributed to methylene group $(\mathrm{CH})$ (Figure
6). From the contribution of various groups to NMR spectra, it may deduced that cane molasses from sugar refinery industry could directly serve as an inexpensive source of biodegradable polymer and that the bacterial biomass produced PHA mainly in the form of PHB when grown under optimized condition.

\section{Conclusion}

Dispersion method gave maximum $\mathrm{PHB}$ recovery and purity of 95.0 \pm 0.5 and $97.0 \pm 0.29$, respectively in comparison to alkali treatment and ATPS extraction. PHB recovery was further enhanced by optimizing the three variables affecting dispersion separation. Maximum PHB recovery of $98.20 \pm 0.05 \%$ with $99.0 \pm 0.05 \%$ purity was obtained under optimized condition comprising: incubation temperature $37^{\circ} \mathrm{C}$, incubation time $28 \mathrm{~h}$ and hypochlorite concentration of $30 \%$ (v/v). Chloroform-hypochlorite dispersion showed efficient PHB recovery from Alcaligenes cells in comparison to other conventional recovery method. Previously, PHB recovery and purity of 80 and 95\% respectively were obtained with chloroform extraction [18] PHB recovered by enzymatic treatment (pancreatin) gave maximum recovery and purity of 93.5 and $91.2 \%$, respectively in Bukerholdria cepacia [19]. Enhanced PHB recovery with high purity from chosen strain (Alcaligenes sp.), obtained in the present study by dispersion method can minimize the overall downstream processing cost. Current methodology may be adopted for efficient PHB recovery from large cell density harvested from bioreactors at industrial level. PHB recovered by dispersion method suggests their crystalline behavior owing to their resistance towards chloroform, may find application in tissue engineering and food packaging.

\section{Acknowledgements}

We would like to pay our sincere thanks to Department of Biotechnology (GOI) for providing financial support in the research work. We would also like to acknowledge Prof. S.B. Roy, Department of Physics, Banaras Hindu University, India for providing FTIR facility. We would be grateful to Central Instrumentation Laboratory, UIET, Punjab University for providing TEM facility.

\section{References}

1. Lu JN, Tappel RC, Nomura CT (2009) Mini-review: biosynthesis of poly(hydroxyalkanoates). Polym Rev 49: 226-248.

2. Verlinden RA, Hill DJ, Kenward MA, Williams CD, Piotrowska-Seget Z, et al. (2011) Production of polyhydroxyalkanoates from waste frying oil by Cupriavidus necator. AMB Express 1: 11.

3. Anderson AJ, Dawes EA (1990) Occurrence, metabolism, metabolic role, and industrial uses of bacterial polyhydroxyalkanoates. Microbiol Rev 54: 450-472.

4. Madison LL, Huisman GW (1999) Metabolic engineering of poly(3hydroxyalkanoates): from DNA to plastic. Microbiol Mol Biol Rev 63: 21-53.

5. Tamer IM, Moo YM, Chisti Y (1998) Optimization of poly ( $\beta$-hydroxybutyric acid) recovery from Alcaligenes latus: Combined mechanical and chemical treatments. Bioprocess Eng 19: 459-468.

6. Dias JM, Lemos PC, Serafim LS, Oliveira C, Eiroa M, et al. (2006) Recent advances in polyhydroxyalkanoate production by mixed aerobic cultures: from the substrate to the final product. Macromol Biosci 6: 885-906.

7. Johnson K, van Geest J, Kleerebezem R, van Loosdrecht MC (2010) Shortand long-term temperature effects on aerobic polyhydroxybutyrate producing mixed cultures. Water Res 44: 1689-1700.

8. Khanna S, Srivastava AK (2005) Statistical media optimization studies for growth and PHB production by Ralstonia eutropha. Process Biochem 4: 2173-2182.

9. Philip S, Keshavarz T, Roy I (2007) Polyhydroxyalkanoates: biodegradable polymers with a range of applications. J Chem Technol Biotechnol 82: 233-247.

10. Chen GQ (2009) A microbial polyhydroxyalkanoates (PHA) based bio- and materials industry. Chem Soc Rev 38: 2434-2446. 
Citation: Tripathi AD, Srivastava SK (2015) Statistical Optimization of Parameters Affecting Polyhydroxybutyrate (PHB) Recovery by Dispersion Method from Alcaligenes Cells and Its Characterization. J Bioprocess Biotech 5: 238 doi:10.4172/2155-9821.1000238

11. Tripathi AD, Srivastava SK (2011) Novel approach for optimization of fermentative condition for polyhydroxybutyrate (PHB) production by Alcaligenes sp. using Taguchi (DOE) methodology. Afr J Biotechnol 10: 7219-7224.

12. Tripathi AD, Srivastava SK (2011) Kinetic Study of Biopolymer (PHB) synthesis in Alcaligenes sp. in submerged fermentation process using TEM. J Pol Sci Environ 19: 732-738.

13. Heinrich D, Madkour MH, Al-Ghamdi MA, Shabbaj II, Steinbüchel A (2012) Large scale extraction of poly(3-hydroxybutyrate) from Ralstonia eutropha $\mathrm{H} 16$ using sodium hypochlorite. AMB Express 2: 59.

14. Hahn SK, Chang YK, Kim BS, Chang HN (1994) Optimization of microbial poly(3-hydroxybutyrate) recover using dispersions of sodium hypochlorite solution and chloroform. Biotechnol Bioeng 44: 256-261.

15. Hahn SK, Chang YK, Lee SY (1995) Recovery and characterization of poly(3hydroxybutyric acid) synthesized in Alcaligenes eutrophus and recombinant Escherichia coli. Appl Environ Microbiol 61: 34-39.
16. Ramsay JA, Berger E, Ramsay BA, Chavarie C (1990) Recovery of poly-3hydroxyalkanoic acid granules by a surfactant-hypochlorite treatment. Biotech Technol 4: 221-26.

17. Kansiz M, Billman-Jacobe H, McNaughton D (2000) Quantitative determination of the biodegradable polymer Poly(beta-hydroxybutyrate) in a recombinan Escherichia coli strain by use of mid-infrared spectroscopy and multivariative statistics. Appl Environ Microbiol 66: 3415-3420.

18. Mahapatra K, Suresh Kumar M, Chakrabarti T (2007) Production and recovery process of polyhydroxybutyrate (PHB) from waste activated sludge. J Environ Sci Eng 49: 164-169.

19. Wang $Y$, Zhou XH, Hu JJ, Zhang QG (2012) Study on Extraction and Identification of PHB from $\mathrm{H}_{2}$ Production Fermentation Residue by Photosynthetic Bacteria. Adv Mater Res 518-523: 108-115. 